\title{
Penjadwalan Produk Menggunakan Teknik Enumerasi
}

\author{
Product Scheduling Using Enumeration Techniques
}

\author{
Evi Febianti, Yusraini Muharni, M. Naufal Azhary \\ Jurusan Teknik Industri, Universitas Sultan Ageng Tirtayasa \\ E-mail: evi@untirta.ac.id, yusmuharni@gmail.com, naufalazhar4@gmail.com
}

\begin{abstract}
Abstrak
Penjadwalan produksi merupakan penentuan aliran produksi agar sesuai dengan waktu yang ditentukan. Unit CRM PT XYZ menjadwalkan kegiatan produksi menggunakan aturan First Come First Served (FCFS). Perusahaan harus tepat waktu dalam untuk memenuhi permintaan konsumen. Jika perusahaan terlambat dalam pengiriman, maka dikenakan penalti atau biaya keterlambatan. Penelitian dilakukan untuk mengetahui job mana yang dilakukan terlebih dahulu untuk menghasilkan nilai makespan dan waktu alir rata-rata yang terkecil. Metode yang digunakan dalam penelitian ini adalah metode Heuristic, yaitu Campbell, Dudek and Smith (CDS), Algoritma Pour Heuristik, dan Teknik Enumerasi. Hasil penelitian menunjukkan bahwa penjadwalan menggunakan metode Campbell, Dudek dan Smith (CDS) menghasilkan makespan 339,16 jam dan waktu alir rata-rata 246,10 jam, Heuristic Pour Algorithm menghasilkan makepan 339,16 jam dan waktu alir rata-rata 237, 25 jam dan Teknik Enumerasi menghasilkan makespan 339,16 jam dan waktu alir rata-rata 230,19 jam. Metode yang dipilih adalah metode Teknik Enumerasi karena menghasilkan makespan dan waktu alir rata-rata terkecil.
\end{abstract}

Kata kunci : CDS, Teknik Enumerasi, Makespan, Heuristik Pour, Penjadwalan

\begin{abstract}
Production scheduling is the determination of the production flow to match the specified time. CRM Unit of PT XYZ schedules production using the First Come First Served (FCFS) rule. Companies must be on time to meet consumer demands. If the company is late in delivery, there will be a penalty or late fee. The research was conducted to find out which job is done first to produce the smallest makespan value and mean flow time. The method used in this research is the Heuristic method, namely Campbell, Dudek and Smith (CDS), Pour Heuristic Algorithm, and Enumeration Techniques. The results showed that scheduling using the Campbell, Dudek and Smith (CDS) method resulted in makespan 339,16 hours and mean flow time of 246,10 hours, the Heuristic Pour Algorithm resulted in makespan 339.16 hours and mean flow time 237.25 hours and Enumeration Technique produces makespan 339.16 hours and mean flow time is 230.19 hours. The method chosen is the Enumeration Technique because it produces the smallest makespan and mean flow time.
\end{abstract}

Keywords : CDS, Enumeration Techniques, Makespan, Pour Heuristics, Scheduling

\section{Pendahuluan}

Penjadwalan dapat diartikan sebagai sebuah proses pengalokasian sumber daya untuk memilih sekumpulan tugas dalam jangka waktu tertentu. Dalam persoalan penjadwalan produksi ada 2 jenis, yaitu penjadwalan flow shop dan penjadwalan job shop (Baker, 2009). Kriteria penjadwalan berdasarkan waktu dapat dibedakan atas minimasi makespan dan pemenuhan due date (Pinedo, 2012). Adapun tujuan dari penjadwalan produksi umumnya ialah untuk mengoptimalkan dimensi tertentu, yaitu makespan (Febianti, 2017). Makespan adalah total waktu penyelesaian suatu penjadwalan yang diperlukan untuk menyelesaikan keseluruhan pekerjaan atau job yang akan dijadwalkan (Baker, 2009). Masalah penjadwalan seringkali diakibatkan ketika terdapat $\mathrm{n}$ job yang akan di proses pada $\mathrm{m}$ buah mesin yang harus ditetapkan, mana yang harus dikerjakan lebih dahulu dan bagaimana urutan prosesnya, serta pengalokasian operasi pada mesin, sehingga diperoleh 
proses produksi yang terjadwal. Hal tersebut mengharuskan perusahaan untuk dapat menyesuaikan antara job dengan mesin yang ada (Pinedo, 2012). Produk yang dihasilkan akan tepat waktu sampai ke konsumen. Metode CDS merupakan salah satu metode penjadwalan produksi yang dapat meminimasi makespan dan menghasilkan solusi yang mendekati optimal (Widodo, 2014).

Pour (2010) mengembangkan algoritma heuristik baru dalam menyelesaikan penjadwalan flow shop (salah satu jenis penjadwalan produksi dimana setiap $\mathrm{n}$ job akan melalui setiap $\mathrm{m}$ mesin dengan urutan yang seragam) dengan tujuan meminalkan makespan (total waktu penyelesain job) yaitu berdasarkan pendekatan kombinasi. Teknik Enumerasi adalah pencacahan satu per satu job untuk menghasilkan nilai makespan yang optimal (Pour, 2010). Selain makespan di dalam ukuran keberhasilan dari suatu pelaksanaan aktivitas penjadwalan adalah dengan menggunakan kriteria flow time yang merupakan rentang waktu antara saat suatu pekerjaan dapat dimulai dan saat pekerjaan selesai dikerjakan. Sehingga flow time sama dengan waktu pemrosesan ditambah dengan waktu menunggu sebelum diproses (Bedworth, 1987).

PT XYZ merupakan salah satu perusahaan manufaktur, yang bergerak dalam bidang industri baja. PT XYZ memiliki beberapa unit produksi, diantaranya adalah Pabrik Baja Lembaran Dingin (Cold Rolling Mill/CRM), dan Pabrik Baja Lembaran Panas (Hot Strip Mill/HSM). Pengambilan data dilakukan di unit produksi Pabrik Baja Lembaran Dingin (Cold Rolling Mill/CRM), karena menerima order paling banyak diantara yang lain. Produk utama dari unit CRM ini ada 2 macam bentuk yaitu CRC (cold roll coil) yang bentuk akhirnya berupa gulungan baja dan CRS (cold roll sheet) yang bentuk akhirnya berupa lembaran-lembaran, pembuatanya ada yang HRPO, soft, dan full hard.

Tingkat permintaan tertinggi untuk produk CRC full hard sebesar 16.580 ton, perusahaan dituntut untuk tepat waktu dalam mengerjakan permintaan dari konsumen. Dampak jika produksi terlambat adalah perusahaan dapat dikenakan pinalti atau mengeluarkan biaya atas keterlambatan pengiriman kepada konsumen, bahkan dampak buruknya konsumen tidak akan order lagi. Hal ini akan menjadi sesuatu yang buruk bagi perusahaan seperti konsumen berpindah ke perusahaan lain, dengan kualitas sama. Waktu pengerjaan berbeda untuk setiap produk, sehingga dibutuhkan penjadwalan job, agar semua pesanan dapat dipenuhi tepat waktu. Dalam hal ini dibutuhkan pengambilan keputusan untuk menentukan penjadwalan produksi yang sesuai agar mendapatkan pengerjaan urutan job yang terbaik.

Berdasarkan permasalahan tersebut penelitian ini bertujuan untuk menentukan penjadwalan produksi yang lebih baik, dimana menghasilkan makespan minimum dan waktu mean flow time minimum. Penyelesaikan permasalahan penjadwalan menggunakan metode CDS, metode Algoritma Heuristik Pour dan Teknik Enumerasi, kemudian dibandingkan hasil makespan dan mean flow time dari ketiga metode tersebut dan dipilih metode dengan nilai makespan dan mean flow time terkecil dan pengerjaan urutan job terbaik.

\section{Tinjauan Pustaka}

\subsection{Penjadwalan Produksi}

Penjadwalan produksi merupakan salah satu fungsi dari pengawasan produksi yang mempunyai peranan yang cukup penting karena dapat mempengaruhi keberhasilan pengawasan produksi itu sendiri. Pada beberapa perusahaan, kegagalan atau kesalahan dalam menyusun penjadwalan produksi tidak hanya dapat mengacaukan usaha pengawasan produksinya, tetapi juga dapat mempengaruhi hal-hal lain dalam perusahaan seperti jumlah produk yang dihasilkan. Penjadwalan produksi berfungsi untuk membuat agar arus produksi dapat berjalan lancar sesuai dengan waktu yang telah direncanakan. Sehingga dapat dikatakan bahwa penjadwalan produksi dilakukan agar mesin-mesin dapat bekerja sesuai dengan kapasitas yang ada dan biaya yang seminimal mungkin, serta kuantitas produk yang diinginkan sesuai waktu yang telah ditentukan (Muharni dkk, 2019). 


\subsection{Metode Campbell, Dudek And Smith}

Metode Campbell, Dudek, and Smith (CDS) merupakan salah satu metode penjadwalan produksi yang dapat meminimasi makespan dan menghasilkan solusi yang mendekati optimal (Ginting, 2009). Metode CDS mencari urutan prioritas terbaik dengan mengkombinasikan stasiun kerja yang ada menjadi dua kelompok mesin. Dari dua kelompok mesin tersebut kemudian dicari dengan mengutamakan waktu proses tercepat. Bila waktu proses terkecil terletak di mesin pertama, job tersebut diletakkan di urutan depan, sedangkan bila waktu proses terkecil terletak di mesin kedua, job tersebut diletakkan di urutan belakang. Adapun langkah-langkah penjadwalan algoritma CDS adalah sebagai berikut: (Ginting, 2009)

1. Tentukan jumlah iterasi, yaitu jumlah mesin -1

2. Ambil penjadwalan pertama $(\mathrm{K}=1)$. Untuk seluruh job yang ada, carilah nilai $\mathrm{t}{ }_{\mathrm{i}, 2}$ yang minimum yang merupakan waktu proses pada mesin pertama dan kedua, dimana $t_{i, 1}=t_{i, 1}$ dan $\mathrm{t}_{\mathrm{i}, 2}=\mathrm{t}_{\mathrm{i}, 2}$. Lakukan juga untuk iterasi selanjutnya.

3. Lakukan aturan Johnson. Jika waktu minimum didapat pada mesin pertama, misal (ti,1) selanjutnya tempatkan tugas tersebut pada awal deret penjadwalan dan bila waktu minimum didapat pada mesin kedua (misal $\mathrm{t}_{\mathrm{i}, 2}$ ), tugas tersebut ditempatkan pada posisi akhir dari deret penjadwalan.

4. Pindahkanlah tugas-tugas tersebut dari daftarnya dan susun dalam bentuk deret penjadwalan. Jika masih ada job yang tersisa, ulangi kembali langkah 1, sebaliknya bila tidak ada job yang tersisa, berarti penjadwalan telah selesai. Dengan demikian, waktu proses dari kedua mesin yaitu mesin pertama $\left(t^{*}{ }_{i, 1}\right)$ dan mesin kedua $\left(t_{i, 2}\right)$ pada penjadwalan ke-k adalah:

$$
\begin{array}{ll}
\mathrm{t}_{\mathrm{i}, 1} & \sum=1 \mathrm{t}_{\mathrm{i} .} \mathrm{K} \\
\mathrm{t} *_{\mathrm{i}, 2} & \sum=1 \mathrm{t}_{\mathrm{i}} \cdot \mathrm{m}-\mathrm{k}+1
\end{array}
$$

Jika jadwal ke-k = m-1 sudah tercapai berarti penjadwalan sudah selesai.

Metode CDS ini menggunakan algoritma Johnson. Algoritma Johnson merupakan suatu algoritma yang digunakan untuk mendaptkan optimal sequence (pengurutan penjadwalan yang optimal) untuk jenis flow Shop. Adapun tahapan dari algoritma Johnson adalah sebagai berikut (Baroto, 2002):

1. Buatlah daftar waktu proses untuk seluruh pekerjaan-pekerjaan tersebut, baik pada mesin pertama (M-1) dan mesin terakhir (M-2).

2. Carilah seluruh waktu proses untuk seluruh pekerjaan, tentukan waku proses yang minimal (tir,ti2).

3. Jika waktu proses minimal berada pada mesin pertama (M-1), tempatkan pekerjaan tersebut paling awal yang mungkin dalam urutan, jika terletak pada mesin kedua (M-2), tempatkan pekerjaan-pekerjaan tersebut paling akhir yang mungkin dalam urutan.

4. Hilangkan pekerjaan yang telah ditugaskan (telah ditempatkan dalam urutan dan sebagai hasil dari langkah 3) dan ulangi langkah 2 dan langkah 3 sehingga seluruh pekerjaan telah diurutkan. 


\subsection{Metode Algoritma Heuristik Pour}

Pour (2010) mengembangkan algoritma heuristik baru dalam menyelesaikan penjadwalan flow shop (salah satu jenis penjadwalan produksi dimana setiap $\mathrm{n}$ job akan melalui setiap $\mathrm{m}$ mesin dengan urutan yang seragam) dengan tujuan meminimalkan makespan (total waktu penyelesain job) yaitu berdasarkan pendekatan kombinasi. Hal ini dilakukan dengan cara mengganti setiap job dengan job yang lainnya dalam urutan sampai ditemukan kombinasi urutan yang dapat memenuhi kriteria tujuan. Dalam metode ini diasumsikan bahwa semua job diproses secara terpisah untuk setiap mesinnya. Berikut adalah notasi yang digunakan:

1. $\mathrm{P}_{\mathrm{ij}}=$ waktu proses dari job $\mathrm{i}$ pada mesin $\mathrm{j}$.

2. $\mathrm{C}_{\mathrm{ij}}=$ rentang waktu antara saat $j o b \mathrm{i}$ pada mesin $\mathrm{j}$ dimulai $(\mathrm{t}=0)$ sampai job itu selesai.

3. $\mathrm{C}_{\mathrm{i}}=$ sum of completion time untuk job i pada semua mesin.

4. Fmax = rentang waktu antara saat pekerjaan tersedia atau dapat dimulai sampai pekerjaan itu selesai (makespan).

Adapun langkah-langkah pengerjaan Algoritma Heuristik Pour:

a. Memilih job secara acak sebagai urutan pertama sementara dalam urutan pengerjaan.

b. Menempatkan job-job lain (selain job yang sudah dipilih sebagai urutan pertama) pada urutan berikutnya.

c. Memilih waktu proses terkecil untuk masing-masing mesin.

d. Melakukan penambahan waktu proses secara increasing time pada $P_{i}$ yang lain, selain $P_{i j}$ paling minimal yang terpilih sebelumnya.

e. Menghitung sum of completion time $\left(\mathrm{C}_{\mathrm{i}}\right)$ atau jumlah waktu dimana setiap pekerjaan dianggap selesai.

f. Mengurutkan $\mathrm{C}_{\mathrm{i}}$ dengan aturan increasing job untuk diletakkan pada urutan setelah job yang sudah dipilih untuk urutan pertama sementara.

g. Setelah diperoleh urutan sementara, maka hitunglah Fmax-nya.

h. Lakukan ulang langkah pada poin a sampai g untuk setiap job yang ada sampai diperoleh Fmax paling minimal, yang akan ditempatkan sebagai urutan pertama dari urutan job.

i. Lakukan ulang langkah pada poin a sampai h semua job berada pada urutan pengerjaan.

\subsection{Teknik Enumerasi}

Teknik enumerasi adalah pencacahan satu per satu job untuk menghasilkan nilai makespan yang optimal, untuk menghitung nilai makespan pada perhitungan teknik enumerasi ini digunakan secara manual dengan bantuan Microsoft Excel. Penyelesaian yang akan dilakukan dengan teknik enumerasi ini untuk mendapatkan urutan pengerjaan pekerjaan yang optimal sehingga akan didapatkan nilai fungsi tujuan (nilai makespan) yang minimum. Adapun menurut Widodo, dkk (2014) urutan proses penyelesaian permasalahan dengan teknik enumerasi ini adalah sebagai berikut:

a. Tahap 1: Pembangkitan secara acak urutan pekerjaan

Pada tahap ini dilakukan pembangkitan secara acak urutan pekerjaan yang mungkin akan terjadi.

b. Tahap 2: Perhitungan nilai makespan

Pada tahap ini setiap urutan jadwal (pekerjaan) yang dibangkitkan pada tahap ini akan dilakukan perhitungan makespan.

c. Tahap 3: Pemilihan solusi terbaik

Pada tahap ini semua urutan penjadwalan pekerjaan yang telah dihitung nilai makespan pada tahap sebelumnya kemudian akan dipilih solusi terbaik yaitu berdasarkan nilai makespan terkecil. Jika tidak menggunakan semua total enumerasi, dikatakan bahwa menjadi parsial enumerasi.

\section{Hasil dan Pembahasan}

Data yang dikumpulkan adalah data sekunder pada bulan November 2019 yaitu data permintaan produk, kapasitas setiap stasiun kerja, waktu set up, waktu proses, rating factor dan allowance. Kemudian data-data tersebut diuji dengan menggunakan uji keseragaman data dan uji kecukupan data. Jika data tersebut sudah seragam dan cukup, maka dilakukan perhitungan waktu siklus, waktu 
normal, waktu baku, waktu penyelesaian job, serta penjadwalan produksi metode perusahaan. Kemudian dilakukan perhitungan untuk mencari nilai makespan dan waktu rata-rata flow time menggunakan metode CDS, metode Algoritma Heuristik Pour dan Teknik Enumerasi.

Setelah didapatkan nilai makespan dan mean flow time dari ketiga metode tersebut, kemudian bandingkan dan ambil nilai makespan dan mean flow time yang terkecil (Widodo, 2014). Pada proses pembuatan produk CRC, mesin yang digunakan yaitu Continous Pickling Line (CPL), Continous Tandem Cold Mill (CTCM) dan Electrolytic Cleaning Line (ECL). Tahap proses produksi yaitu diawali produk baja lembaran panas yang dibersihkan lapisan oksida pada mesin CPL, kemudian diratakan dan dipotong pada mesin CTCM dan selanjutnya masuk ke mesin ECL untuk menghilangkan sisa lapisan minyak dan oli yang ada pada permukaan CRC tersebut. Proses produksi dilakukan dengan cara melihat turutan job, dengan mempertimbangkan job mana yang paling banyak dipesan oleh konsumen.

\subsection{Pengolahan Data}

Pengolahan data yang dilakukan dalam penelitian ini terdiri dari uji keseragaman, uji kecukupan, penentuan waktu siklus, perhitungan waktu normal, perhitungan waktu baku, perhitungan waktu penyelesaian job, penjadwalan usulan eksisting, penjadwalan produksi dengan metode Campbell, Dudek, and Smith (CDS), dan penjadwalan produksi dengan metode Algoritma Heuristik Pour serta teknik Enumerasi, dengan menghitung makespan eksisting perusahaan. Kemudian dilakukan perhitungan dengan mencari nilai makespan dan mean flow time dengan menggunakan metode CDS, metode Algoritma Heuristik Pour dan Teknik Enumerasi.

\subsubsection{Uji Keseragaman}

Berdasarkan Tabel 1, dapat diketahui bahwa data yang diperoleh berada diantara batas kontrol atas dan bawah atau tidak ada data yang berada di luar batas kontrol, sehingga data tersebut seragam. Berikut merupakan rekapitulasi hasil uji keseragaman data semua job disetiap mesin, tersaji pada Tabel 1. Dapat diketahui bahwa semua hasil job yang telah diuji, memiliki nilai rata-rata $\overline{\mathrm{X}}$ berada diantara nilai BKA dan $\mathrm{BKB}$, sehingga dapat dikatakan bahwa semua data termasuk data yang seragam.

Tabel 1. Rekapitulasi Hasil Uji Keseragaman Data Masing-Masing Job di Tiap Mesin

\begin{tabular}{ccccccc}
\hline Job & $\begin{array}{c}\text { Ukuran } \\
(\mathrm{mm})\end{array}$ & Mesin & $\overline{\mathrm{X}}$ & BKA & BKB & Ket \\
\hline \multirow{3}{*}{1} & Heavy & $C P L$ & 371,8 & 392,44 & 351,24 & Seragam \\
& $3 \mathrm{~mm}$ & $E C L$ & 338,3 & 344,99 & 331,65 & Seragam \\
& & $C P L$ & 520,5 & 628,57 & 612,58 & Seragam \\
& Medium & $C T C M$ & 621 & 531,38 & 518,23 & Seragam \\
2 & $0,2 \mathrm{~mm}$ & $E C L$ & 1195 & 1203,2 & 1185,8 & Seragam \\
& & $C P L$ & 524,8 & 531,38 & 518,23 & Seragam \\
\multirow{2}{*}{3} & Lite & $C T C M$ & 621,3 & 629,5 & 613,11 & Seragam \\
& $0,2 \mathrm{~mm}$ & $E C L$ & 372,1 & 392,17 & 352,16 & Seragam \\
& & $C P L$ & 1195 & 1203,2 & 1185,8 & Seragam \\
4 & Heavy & $C T C M$ & 338,3 & 344,99 & 331,65 & Seragam \\
& $2 \mathrm{~mm}$ & $E C L$ & 620,8 & 628,42 & 613,31 & Seragam \\
& Medium & $C P L$ & 471,2 & 491,96 & 450,61 & Seragam \\
\multirow{2}{*}{5} & $0,3 \mathrm{~mm}$ & $C T C M$ & 446,7 & 474,45 & 419 & Seragam \\
& & $E C L$ & 720,2 & 728,34 & 712,24 & Seragam \\
\hline
\end{tabular}




\subsubsection{Uji Kecukupan}

Uji kecukupan data dilakukan untuk mengetahui indikator banyaknya data yang harus dikumpulkan dan agar data yang terkumpul secara objektif, berikut ini merupakan rekapan perhitungan uji kecukupan data job 1 pada mesin CPL, tersaji pada Tabel 2.

Tabel 2. Rekapitulasi Hasil Uji Kecukupan Data Masing-Masing Job di Tiap Mesin

\begin{tabular}{|c|c|c|c|c|c|}
\hline Job & Ukuran (mm) & Mesin & $\begin{array}{c}\text { Jumlah Data } \\
\text { Diambil } \\
\end{array}$ & $\mathrm{N}^{\prime}$ & KET \\
\hline \multirow{4}{*}{1} & \multirow{4}{*}{ Heavy $3 \mathrm{~mm}$} & $C P L$ & 20 & 1,166 & Cukup \\
\hline & & CTCM & 20 & 0,148 & Cukup \\
\hline & & $E C L$ & 20 & 0,063 & Cukup \\
\hline & & $C P L$ & 20 & 0,06 & Cukup \\
\hline \multirow[t]{3}{*}{2} & \multirow[t]{3}{*}{ Medium $0,2 \mathrm{~mm}$} & CTCM & 20 & 0,21 & Cukup \\
\hline & & $E C L$ & 20 & 0,02 & Cukup \\
\hline & & $C P L$ & 20 & 0,06 & Cukup \\
\hline \multirow[t]{3}{*}{3} & \multirow[t]{3}{*}{ Lite $0,2 \mathrm{~mm}$} & CTCM & 20 & 0,29 & Cukup \\
\hline & & $E C L$ & 20 & 0,02 & Cukup \\
\hline & & $C P L$ & 20 & 1,098 & Cukup \\
\hline \multirow[t]{3}{*}{4} & \multirow[t]{3}{*}{ Heavy $2 \mathrm{~mm}$} & CTCM & 20 & 0,148 & Cukup \\
\hline & & $E C L$ & 20 & 0,056 & Cukup \\
\hline & & $C P L$ & 20 & 0,731 & Cukup \\
\hline \multirow[t]{2}{*}{5} & \multirow[t]{2}{*}{ Medium $0,3 \mathrm{~mm}$} & CTCM & 20 & 1,464 & Cukup \\
\hline & & $E C L$ & 20 & 0,047 & Cukup \\
\hline
\end{tabular}

Berdasarkan Tabel 2 di atas, dapat dilihat bahwa semua hasil uji kecukupan data untuk masingmasing job di setiap mesin memiliki niali $\mathrm{N}^{\prime}<\mathrm{N}$, artinya data yang ada telah mencukupi.

\subsubsection{Waktu Siklus}

Waktu siklus merupakan yang diperoleh dari waktu penyelesaian produksi yang telah lulus uji keseragaman dan kecukupan data. Berikut ini merupakan waktu siklus yang digunakan untuk setiap job yang dikerjakan oleh mesin, tersaji pada Tabel 3 .

Tabel 3. Data Waktu Siklus Produksi CRC Full Hard

\begin{tabular}{ccccc}
\hline \multirow{2}{*}{ Job } & \multirow{2}{*}{ Ukuran } & \multicolumn{3}{c}{ Waktu Siklus (detik) } \\
& & CPL & CTCM & ECL \\
\hline 1 & Heavy $3 \mathrm{~mm}$ & 371,84 & 338,32 & 620,6 \\
2 & Medium $0,2 \mathrm{~mm}$ & 524,8 & 621,08 & 1195 \\
3 & Lite $0,2 \mathrm{~mm}$ & 524,81 & 621,31 & 372,2 \\
4 & Heavy $2 \mathrm{~mm}$ & 1194,6 & 338,32 & 620,9 \\
5 & Medium $0,3 \mathrm{~mm}$ & 471,29 & 446,73 & 720,3 \\
\hline
\end{tabular}

\subsubsection{Waktu Normal}

Waktu normal adalah waktu penyelesaian pekerjaan yang diselesaikan oleh pekerja dalam kondisi wajar dan kemampuan rata. Berikut ini merupakan waktu normal untuk masing-masing job di setiap mesin, tersaji pada Tabel 4. 
Tabel 4. Data Waktu Normal Produksi CRC Full Hard

\begin{tabular}{ccccc}
\hline \multirow{2}{*}{ Job } & \multirow{2}{*}{ Ukuran } & \multicolumn{3}{c}{ Waktu Normal (detik) } \\
& & CPL & CTCM & ECL \\
\hline 1 & Heavy $3 \mathrm{~mm}$ & 435,05 & 433,06 & 713,66 \\
2 & Medium $0,2 \mathrm{~mm}$ & 204,68 & 794,98 & 1373,75 \\
3 & Lite $0,2 \mathrm{~mm}$ & 614,03 & 795,28 & 427,99 \\
4 & Heavy $2 \mathrm{~mm}$ & 1397,64 & 433,06 & 714 \\
5 & Medium $0,3 \mathrm{~mm}$ & 551,41 & 571,82 & 828,34 \\
\hline
\end{tabular}

\subsubsection{Waktu baku}

Waktu baku adalah waku yang digunakan untuk menyelesaikan suatu siklus pekerjaaan berdasarkan metode pengukuran kerja dengan memperhatikan rating factor dan allowance factor dengan tingkat kecepatan kerja normal. Berikut ini waktu baku untuk masing-masing job di tiap mesin, tersaji pada Tabel 5.

Tabel 5. Data Waktu Baku Produksi CRC Full Hard

\begin{tabular}{ccccc}
\hline \multirow{2}{*}{ Job } & \multirow{2}{*}{ Ukuran } & \multicolumn{3}{c}{ Waktu Baku (detik) } \\
& & $C P L$ & $C T C M$ & $E C L$ \\
\hline 1 & Heavy $3 \mathrm{~mm}$ & 565,57 & 569,9 & 913,49 \\
2 & Medium $0,2 \mathrm{~mm}$ & 266,08 & 1046,2 & 1758,4 \\
3 & Lite $0,2 \mathrm{~mm}$ & 798,24 & 1046,59 & 547,83 \\
4 & Heavy $2 \mathrm{~mm}$ & 1816,93 & 569,9 & 913,92 \\
5 & Medium $0,3 \mathrm{~mm}$ & 716,83 & 752,51 & 1060,27 \\
\hline
\end{tabular}

\subsubsection{Waktu Penyelesaian}

Waktu penyelesaian job di mesin berdasarkan data produksi dengan menjumlahkan waktu baku dikali dengan total pcs/1 (jumlah mesin) akan digunakan untuk menghitung makespan pada penjadwalan produksi. Berikut ini merupakan rekapitulasi waktu penyelesaian tiap job pada tiap mesin dalam satuan detik:

Tabel 6. Data Waktu Penyelesaian Produksi CRC Full Hard (Detik)

\begin{tabular}{ccccc}
\hline \multirow{2}{*}{ Job } & \multirow{2}{*}{ Ukuran } & \multicolumn{3}{c}{ Waktu Penyelesaian (detik) } \\
\cline { 3 - 5 } & & CPL & CTCM & $E C L$ \\
\hline 1 & Heavy $3 \mathrm{~mm}$ & 136302,4 & 137345,9 & 220151,1 \\
2 & Medium $0,2 \mathrm{~mm}$ & 42572,8 & 167392 & 281344 \\
3 & Lite $0,2 \mathrm{~mm}$ & 219516 & 287812,3 & 150653,3 \\
4 & Heavy $2 \mathrm{~mm}$ & 283441,1 & 88904,4 & 142571,5 \\
5 & Medium $0,3 \mathrm{~mm}$ & 146233,3 & 153512 & 216295,1 \\
\hline
\end{tabular}

Contoh Perhitungan:

Waktu Siklus Job 1 (Heavy $3 \mathrm{~mm})$ pada mesin CPL $=\frac{\text { Waktu Bakux Total Coil }}{\text { Jumlah Mesin }}$

$$
\begin{aligned}
& =\frac{565,57 \times 241}{1} \\
& =136302,37 \text { detik }
\end{aligned}
$$


Berikut adalah data waktu penyelesaian produksi CRC Full Hard (Jam) merupakan hasil konversi waktu dalam satuan jam yang sebelumnya masih dalam satuan detik, dengan tujuan agar mempermudah dalam proses perhitungan, berikut ini merupakan data waktu penyelesaian job yang diubah dalam satuan jam tersaji pada Tabel 7.

Tabel 7. Data Waktu Penyelesaian Produksi CRC Full Hard (Jam)

\begin{tabular}{ccccc}
\hline \multirow{2}{*}{ Job } & Ukuran & \multicolumn{3}{c}{ Waktu Penyelesaian (jam) } \\
& & CPL & CTCM & $E C L$ \\
\hline 1 & Heavy $3 \mathrm{~mm}$ & 37,86 & 38,15 & 61,15 \\
2 & Medium $0,2 \mathrm{~mm}$ & 11,83 & 46,5 & 78,15 \\
3 & Lite $0,2 \mathrm{~mm}$ & 60,98 & 79,95 & 41,85 \\
4 & Heavy $2 \mathrm{~mm}$ & 78,73 & 24,7 & 39,6 \\
5 & Medium $0,3 \mathrm{~mm}$ & 40,62 & 42,64 & 60,08 \\
\hline
\end{tabular}

\subsubsection{Penjadwalan Produksi Dengan Metode Perusahaan}

Dalam penelitian ini, penjadwalan produksi eksisting dilakukan dengan sistem first come first serve (FCFS), dengan urutan berdasarkan datangnya pesanan. Berikut ini perhitungan penjadwalan produksi eksisting perusahaan dalam satuan jam tersaji pada Tabel 8.

Tabel 8. Perhitungan Penjadwalan Produksi Dengan Metode Perusahaan

\begin{tabular}{ccccccc}
\hline \multirow{2}{*}{ Mesin } & \multicolumn{5}{c}{ Waktu Penyelesaian (jam) } \\
& & Job 1 & Job 2 & Job 3 & Job 4 & Job 5 \\
\hline \multirow{2}{*}{ CPL } & Mulai & 0 & 38,36 & 50,69 & 112,17 & 191,4 \\
& Selesai & 37,86 & 50,19 & 111,67 & 190,9 & 232,02 \\
\multirow{2}{*}{ CTCM } & Mulai & 37,86 & 76,51 & 123,51 & 203,96 & 229,16 \\
& Selesai & 76,01 & 123,51 & 203,46 & 228,66 & 271,3 \\
\multirow{2}{*}{$E C L$} & Mulai & 76,01 & 137,17 & 215,32 & 257,17 & 296,8 \\
& Selesai & 137,17 & 215,32 & 257,17 & 296,77 & 356,9 \\
\hline
\end{tabular}

Untuk waktu set up diasumsikan sama untuk seluruh mesin dan job.

Contoh perhitungan:

Mesin CPL

Job 1

$$
\begin{aligned}
& =\text { Waktu Mulai }+ \text { Waktu Penyelesaian } \\
& =0+37,86 \\
& =37,86 \mathrm{jam}
\end{aligned}
$$

Job $2=$ Waktu Mulai + Waktu Set $U p+$ Waktu Penyelesaian

$$
\begin{aligned}
& =37,86+0,5+11,83 \\
& =50,19 \text { jam }
\end{aligned}
$$

Makespan $\quad=356,85 \mathrm{jam}$

Mean Flow time $=$ Jumlah waktu penyelesaian mesin terakhir/dengan jumlah job

$$
\begin{aligned}
& =(137,17+215,32+257,17+296,77+356,85) / 5 \\
& =252,65 \mathrm{jam}
\end{aligned}
$$

Berdasarkan Tabel 8, maka didapatkan nilai makespan sebesar 356,9 jam dan mean flow time 252,65 jam dengan urutan job 1 - job 2 - job 3 - job 4 - job 5. Makespan adalah total waktu penyelesaian seluruh job yang dihitung berdasarkan saat job pertama mulai dikerjakan sampai job terakhir selesai di mesin terakhir 


\subsubsection{Penjadwalan dengan metode Campbell, Dudek, and Smith (CDS)}

Metode CDS untuk metode penjadwalan produksi flow shop yaitu mencari urutan prioritas terbaik dengan mengkombinasikan mesin yang ada menjadi dua kelompok mesin. Dari dua kelompok mesin tersebut kemudian dicari nilai yang terkecil dengan mengutamakan waktu proses tercepat. Bila waktu proses terkecil terletak di mesin pertama, job tersebut diletakkan di urutan depan. Sedangkan bila waktu proses terkecil terletak di mesin kedua, job tersebut diletakkan di urutan belakang. Adapun langkahnya adalah sebagai berikut: (Pambudi, 2016)

1. Tentukan jumlah iterasi, yaitu jumlah mesin 3-1 = 2. Dengan demikian banyaknya kombinasi urutan $j o b$ atau iterasi yang dilakukan sebanyak dua kali iterasi.

Iterasi $1(\mathrm{k}=1)$

Berikut ini merupakan waktu proses iterasi 1 yaitu membandingkan waktu di mesin 1 CPL dan Mesin 3 ECL:

Tabel 9. Perbandingan Waktu Proses Iterasi 1

\begin{tabular}{ccc}
\hline \multirow{2}{*}{ Job } & \multicolumn{3}{c}{ Mesin } \\
& EPL & ECL \\
\hline 1 & 37,86 & 61,15 \\
2 & 11,83 & 78,15 \\
3 & 60,98 & 41,85 \\
4 & 78,73 & 39,6 \\
5 & 40,62 & 60,08 \\
\hline
\end{tabular}

Berdasarkan Tabel 9 diketahui bahwa urutan pengerjaan job dari yang terkecil ke terbesar adalah job 2 - job 1 - job 5 -job 3 - job 4. Lakukan juga untuk iterasi k=2.

Waktu proses dari kedua mesin yaitu mesin pertama $\left(t^{*}{ }_{i, 1}\right)$ dan mesin kedua $\left(t *_{i, 2}\right)$ pada penjadwalan ke-k adalah: $\quad \mathrm{t}^{*}, 1, \sum_{j}^{k}=1 \mathrm{ti}, \mathrm{k}$

$$
\Sigma_{j}^{k}=1 \text { ti. } \mathrm{m}-\mathrm{k}+1
$$

Jika jadwal ke-k = m-1 sudah tercapai berarti penjadwalan sudah selesai, lakukan juga untuk iterasi $\mathrm{k}=2$. Berikut ini perhitungan penjadwalan produksi usulan dengan metode CDS iterasi $1(\mathrm{k}=1)$ :

Tabel 10. Perhitungan Penjadwalan Produksi Usulan Metode CDS Iterasi 1

\begin{tabular}{ccccccc}
\hline \multirow{2}{*}{ Mesin } & \multicolumn{5}{c}{ Waktu Penyelesaian Jam ke- } \\
& & Job 2 & Job 1 & Job 5 & Job 3 & Job 4 \\
\hline \multirow{2}{*}{$C P L$} & Mulai & 0 & 12,33 & 50,69 & 91,81 & 153,29 \\
& Selesai & 11,83 & 50,19 & 91,31 & 152,79 & 232,02 \\
\multirow{2}{*}{$C T C M$} & Mulai & 11,83 & 58,83 & 97,48 & 140,62 & 221,07 \\
& Selesai & 58,33 & 96,98 & 140,12 & 220,57 & 245,77 \\
\multirow{2}{*}{$E C L$} & Mulai & 58,33 & 136,98 & 198,63 & 259,21 & 301,56 \\
& Selesai & 136,48 & 198,13 & 258,71 & 301,06 & 341,16 \\
\hline
\end{tabular}

Contoh perhitungan:

Mesin CPL

$\begin{aligned} \text { Job } 1 & =\text { Waktu Mulai }+ \text { Waktu Penyelesaian } \\ & =0+11,83 \\ & =11,83 \mathrm{jam} \\ & =\text { Waktu Mulai }+ \text { Waktu Set } U p+\text { Waktu Penyelesaian } \\ & =11,83+0,5+37,86 \\ & =50,19 \mathrm{jam} \\ \text { Makespan } & =339,16 \mathrm{jam}\end{aligned}$


Mean Flow time $=$ Jumlah waktu penyelesaian job di mesin terakhir/jumlah job

$$
\begin{aligned}
& =(136,47+197,63+257,17+299,56+339,16) / 5 \\
& =246,10 \mathrm{jam} .
\end{aligned}
$$

Berdasarkan Tabel 10, maka didapatkan nilai makespan sebesar 339,16 jam dan mean flow time 246,10 jam dengan urutan job 2 - job 1 - job 5 - job 3 - job 4 .

Iterasi $2(\mathrm{k}=2)$

Berikut ini merupakan waktu proses iterasi 2 yaitu membandingkan waktu di mesin CPL + CTCM dan Mesin CTCM + ECL:

Tabel 11. Perbandingan Waktu Proses Iterasi 2

\begin{tabular}{ccc}
\hline \multirow{2}{*}{ Job } & Mesin \\
& $C P L+C T C M$ & $C T C M+E C L$ \\
\hline 1 & 76,01 & 99,3 \\
2 & 58,32 & 124,65 \\
3 & 140,92 & 121,8 \\
4 & 103,43 & 64,3 \\
5 & 83,26 & 102,72 \\
\hline
\end{tabular}

Berdasarkan Tabel 11, diketahui bahwa urutan pengerjaan job dari yang terkecil ke terbesar adalah job 2 -job 1 - job 5 -job 3 - job 4 .

Rekapitulasi Urutan dan Nilai Makespan Metode Campbell, Dudek, and Smith (CDS).

Berikut ini rekapitulasi urutan dan hasil nilai Makespan pada setiap iterasi yang dihasilkan dengan menggunakan metode CDS :

Tabel 12. Rekapitulasi Urutan, Nilai Makespan dan Mean Flow Time Metode CDS

\begin{tabular}{llll}
\hline Iterasi & Urutan & $\begin{array}{l}\text { Makespan } \\
\text { (Jam) }\end{array}$ & $\begin{array}{l}\text { Mean Flow } \\
\text { Time (jam) }\end{array}$ \\
\hline 1 & $2-1-5-3-4$ & 339,16 & 246,10 \\
2 & $2-1-5-3-4$ & 339,16 & 246,10 \\
\hline
\end{tabular}

Berdasarkan Tabel 12, semua iterasi memiliki nilai makespan yang sama yaitu 339,16 jam dan mean flow time 246,106 dengan urutan setiap job adalah 2-1-5-3-4.

\subsubsection{Hasil Urutan dan Nilai Makespan Dengan Metode Algoritma Heuristik Pour}

Pada Tabel 13 merupakan hasil urutan dan hasil nilai makespan pada setiap kombinasi yang dihasilkan dengan menggunakan metode algoritma heuristik pour.

Tabel 13. Hasil Urutan, Nilai Makespan dan Mean Flow Time Metode Algortima Heuristik Pour

\begin{tabular}{clcc}
\hline Kombinasi & $\begin{array}{l}\text { Urutan } \\
\text { Job }\end{array}$ & Makespan (Jam) & $\begin{array}{c}\text { Mean } \\
\text { Flow } \\
\text { Time } \\
\text { (Jam) }\end{array}$ \\
\hline 1 & $1-4-5-2-3$ & 356,85 & 244,52 \\
2 & $2-4-1-5-3$ & 339,16 & 237,25 \\
3 & $3-4-1-5-2$ & 404,76 & 287,41 \\
4 & $4-1-5-3-2$ & 420,24 & 310,79 \\
5 & $5-4-1-2-3$ & 364,1 & 251,35 \\
\hline
\end{tabular}

Dari Tabel 13 diatas, maka didapat nilai makespan terkecil yaitu kombinasi 2 urutan job 2-4-1-5-3 dengan mean flow time sebesar 237,51 jam. 


\subsubsection{Penjadwalan Produksi Usulan Dengan Teknik Enumerasi}

Teknik Enumerasi adalah pencacahan satu per satu job untuk menghasilkan nilai makespan yang optimal dan dilakukan perhitungan secara manual. Penyelesaian yang akan dilakukan dengan teknik Enumerasi ini untuk mendapatkan urutan pengerjaan pekerjaan yang optimal sehingga akan didapatkan nilai fungsi tujuan (nilai makespan) yang minimum. Pada penelitian ini terdapat 5 job yang akan di jadwalkan maka total kemungkinan penjadwalan urutan pekerjaan yaitu $5 !=2 \times 3 \times 4$ $\mathrm{x} 5=120$ total kemungkinan jadwal urutan pekerjaan. Namun pada penelitian ini hasil perhitungan makespan untuk teknik Enumerasi dilakukan 25 kombinasi. Hal tersebut dilakukan karena hasil perhitungan tidak ada lagi nilai yang lebih baik untuk nilai makespan dan mean flow time dengan kombinasi yang lainnya.

Rekapitulasi urutan dan hasil nilai makespan pada setiap kombinasi yang dihasilkan dengan menggunakan teknik Enumerasi ditampilkan pada Tabel 14.

Tabel 14. Rekapitulasi Urutan, Nilai Makespan dan Mean Flow Time Dengan Teknik Enumerasi

\begin{tabular}{cccc}
\hline Kombinasi & Urutan Job & $\begin{array}{c}\text { Makespan } \\
\text { (Jam) }\end{array}$ & $\begin{array}{c}\text { Mean } \\
\text { Flow } \\
\text { Time } \\
\text { (jam) }\end{array}$ \\
\hline 1 & $1-2-4-5-3$ & 356,85 & 255,85 \\
2 & $1-3-4-5-2$ & 356,85 & 234,07 \\
3 & $1-4-5-2-3$ & 356,85 & 244,53 \\
4 & $1-5-4-2-3$ & 356,85 & 248,62 \\
5 & $1-4-5-3-2$ & 356,85 & 237,27 \\
6 & $2-1-4-5-3$ & 339,16 & 241,56 \\
7 & $2-3-4-1-5$ & 339,16 & 230,19 \\
8 & $2-4-5-1-3$ & 339,16 & 237,04 \\
9 & $2-5-4-1-3$ & 339,16 & 241,13 \\
10 & $2-4-1-3-5$ & 339,16 & 237,25 \\
11 & $3-1-4-5-2$ & 421,76 & 295,12 \\
12 & $3-2-4-1-5$ & 421,76 & 305,53 \\
13 & $3-4-1-5-2$ & 404,76 & 287,41 \\
14 & $3-5-1-4-2$ & 421,76 & 299 \\
15 & $3-4-1-2-5$ & 421,76 & 257,87 \\
16 & $4-1-5-2-3$ & 404,75 & 288,11 \\
17 & $4-2-1-5-3$ & 404,75 & 295,13 \\
18 & $4-3-1-5-2$ & 403,9 & 273 \\
19 & $4-5-1-2-3$ & 404,75 & 287,9 \\
20 & $4-1-5-3-2$ & 420,24 & 310,8 \\
21 & $5-1-4-2-3$ & 364,1 & 255,66 \\
23 & $5-3-4-1-2$ & 364,1 & 240,68 \\
24 & $5-4-1-2-3$ & 364,1 & 251,35 \\
25 & $5-4-1-3-2$ & 364,1 & 244,09 \\
\hline & & &
\end{tabular}

Dari hasil perhitungan dengan teknik Enumerasi tersebut dihasilkan bahwa terdapat 25 kombinasi penjadwalan pekerjaan yang memiliki nilai pada kombinasi 1 sampai dengan kombinasi 5 nilai makespan sebesar 356,85 jam, kombinasi 6 sampai dengan kombinasi 10 menghasilkan nilai makespan 339,16 jam, kombinasi 11, 12, 14, 15 menghasilkan nilai makespan 421,76 jam, kombinasi 13 menghasilkan nilai makespan 404,76 jam, kombinasi 16 dan 17 menghasilkan nilai makespan 404,57 jam, kombinasi 18 menghasilkan nilai makespan 404,76 jam, kombinasi 19 
menghasilkan nilai makespan 404,75 jam, kombinasi 20 menghasilkan nilai makespan 420,24 jam, dan kombinasi 21, 22, 23, 24,25 menghasilkan nilai makespan 364,1 jam.

Tabel 15. Rekapitulasi Urutan, Nilai Makespan dan Mean Flow Time Minimum Tiap Metode

\begin{tabular}{ccccc}
\hline No & Metode Penjadwalan & Urutan Job & Makespan (Jam) & $\begin{array}{c}\text { Mean Flow } \\
\text { Time (jam) }\end{array}$ \\
\hline 1 & Eksisting & $1-2-3-4-5$ & 356,85 & 252,656 \\
2 & Campbell, Dudek, and Smith & $2-1-5-3-4$ & 339,16 & 246,106 \\
3 & Algoritma Heuristik Pour & $2-4-1-5-3$ & 339,16 & 237,51 \\
4 & Teknik Enumerasi & $2-3-4-1-5$ & 339,16 & 230,19 \\
\hline
\end{tabular}

Dari Tabel 15, dapat diketahui bahwa makespan pada penjadwalan eksisting sebesar 356,85 jam, sedangkan makespan penjadwalan usulan metode CDS sebesar 339,16 jam, metode algoritma Heuristik Pour sebesar 339,16 jam, dan teknik Enumerasi sebesar 339,16 jam. Nilai makespan penjadwalan usulan lebih kecil dibanding dengan makespan eksisting, sehingga selisih waktu yang dihasilkan dengan eksisting yaitu sebesar 17,69 jam.

\subsubsection{Gantt Chart}

Gantt Chart digunakan untuk melihat hasil antara penjadwalan sumber daya dan alokasi waktu. Gambar 2 sampai Gambar 5 merupakan Gantt Chart dari hasil penjadwalan dengan metode perusahaan dan penjadwalan usulan menggunakan metode CDS, Algoritma Heuristik Pour dan Teknik Enumerasi.

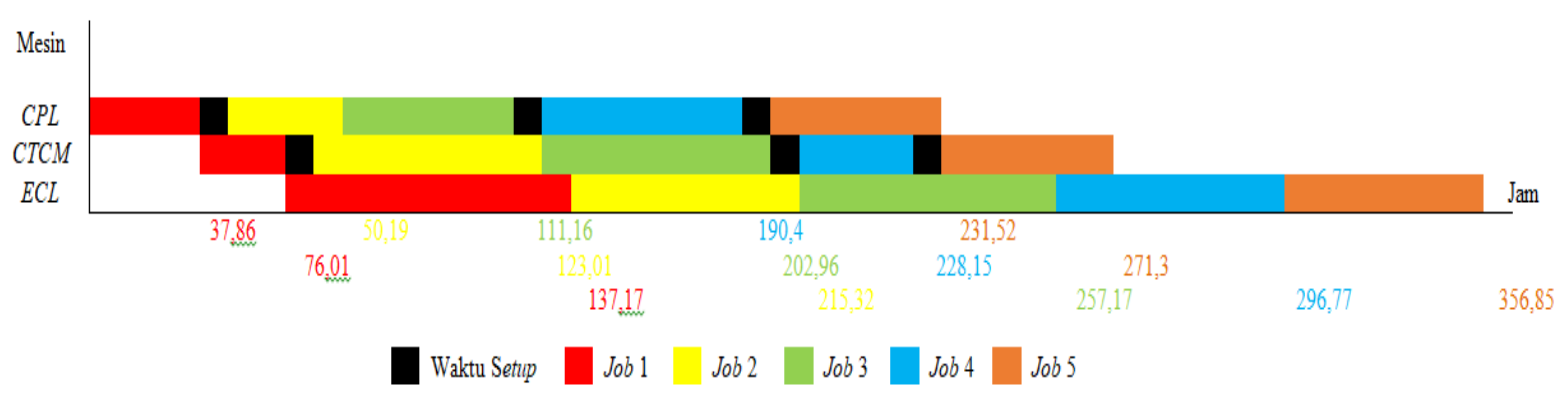

Gambar 2. Gantt Chart Dengan Metode Perusahaan

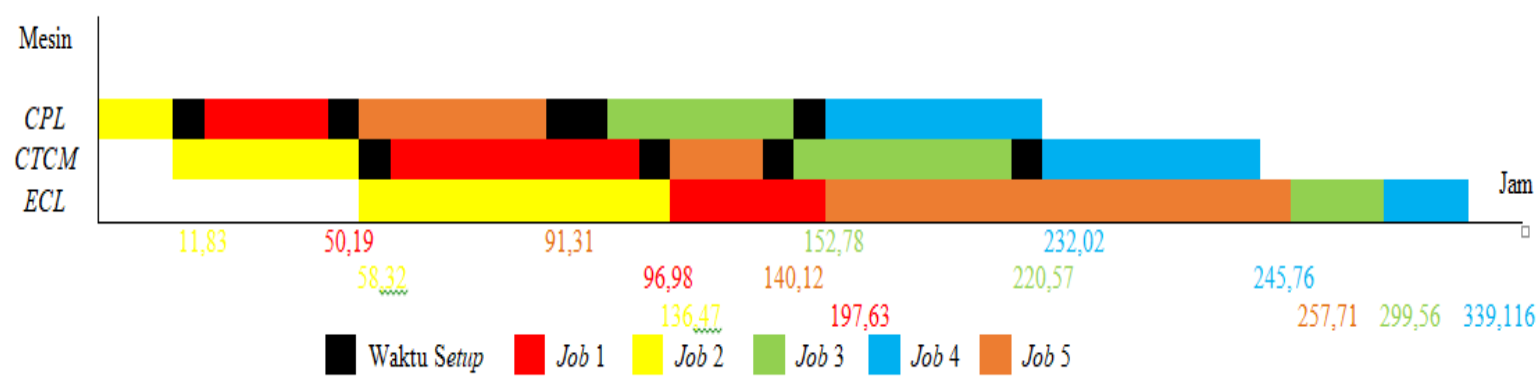

Gambar 3. Gantt Chart Metode CDS 


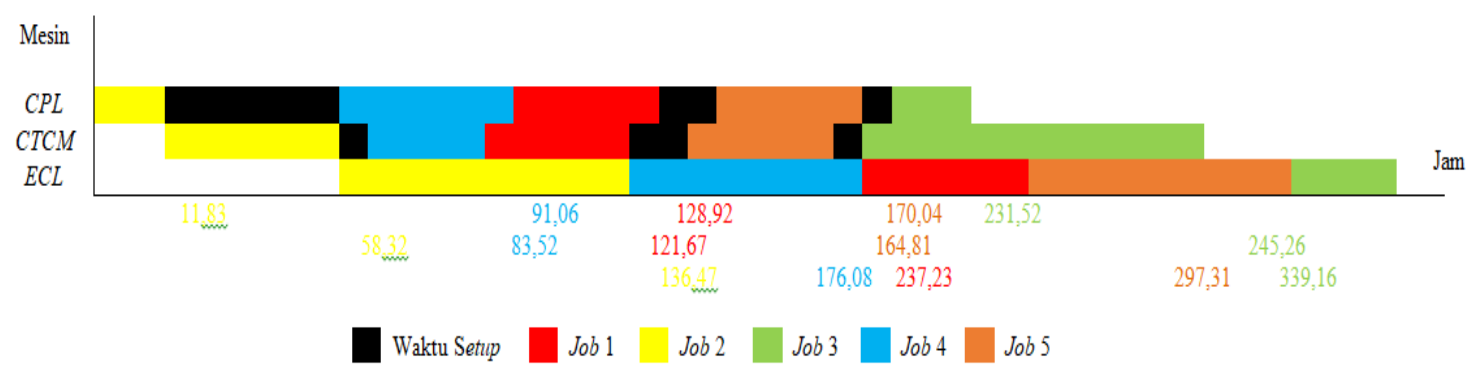

Gambar 4. Gantt Chart Metode Algoritma Heuristik Pour

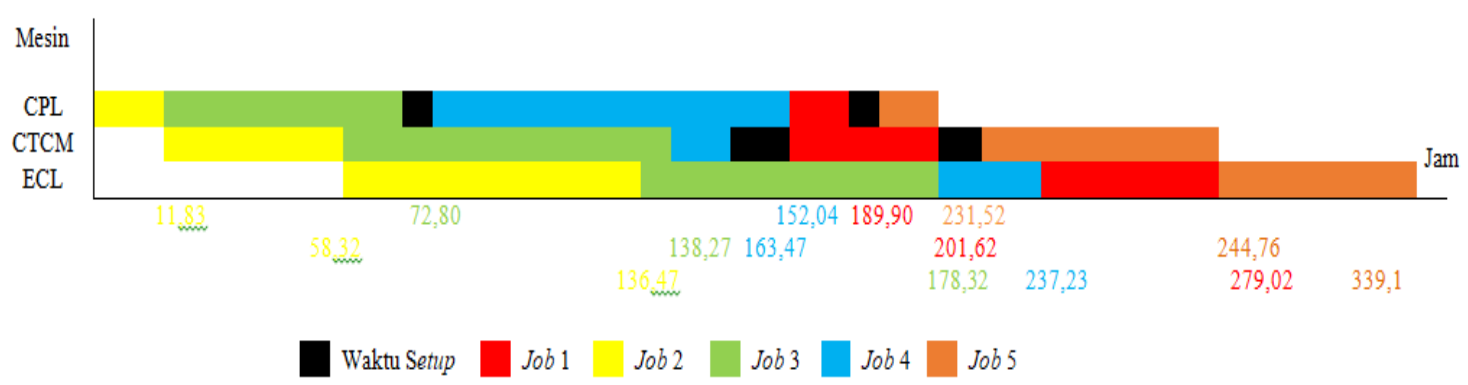

Gambar 5. Gantt Chart Teknik Enumerasi

Dari hasil pengolahan data yang telah dilakukan dengan menggunakan tiga metode, menghasilkan sebagai berikut metode CDS makespan sebesar 339,16 dan mean flow time 246,10 jam, Algoritma Heuristik Pour makespan sebesar 339,16 jam dan mean flow time 237,51 jam dan Teknik Enumerasi makespan sebesar 339,16 jam dan mean flow time 230,19 jam. Urutan job dengan metode CDS adalah job 2-1-5-3-4, metode Algoritma Heusristik Pour adalah 2-4-1-5-3 dan Teknik Enumerasi adalah job 2-3-4-1-5. Teknik Enumerasi adalah metode terbaik yang dapat diterapkan pada penjadwalan produksi di unit produksi CRM untuk produk Full hard, karena memiliki nilai makespan sebesar 339,16 jam dan mean flow time 230,19 jam. Namun memililki kelemahan karena didalam perhitungan harus mencoba seluruh kombinasi

\section{Kesimpulan dan Saran}

Berdasarkan hasil penelitian yang telah dilakukan, maka dapat ditarik beberapa kesimpulan yaitu sebagai berikut:

Penjadwalan eksisting produksi CRC full hard di unit produksi Cold Rolling Mill menghasilkan makespan sebesar 356,85 jam dan mean flow time sebesar 252,65 dengan urutan job 1-2-3-4-5. Nilai makespan dan mean flow time minimum yang dihasilkan pada penjadwalan produksi CRC full hard dengan metode Campbell, Dudek and Smith (CDS) makespan sebesar 339,16 dan mean flow time 246,10 jam, Algoritma Heuristik Pour makespan sebesar 339,16 jam dan mean flow time 237,51 jam dan teknik Enumerasi makespan sebesar 339,16 jam dan mean flow time 230,19 jam. Urutan job terbaik yang dihasilkan pada penjadwalan produksi CRC full hard dengan metode Campbell, Dudek, and Smith (CDS) adalah job 2-1-5-3-4, metode Algoritma Heusristik Pour adalah job 2-4-1-5-3 dan Teknik Enumerasi adalah job 2-3-4-1-5. Teknik Enumerasi adalah metode terbaik yang dapat diterapkan pada penjadwalan produksi di unit produksi CRM untuk produk Full hard, karena memiliki nilai makespan sebesar 339,16 jam dan mean flow time 230,19 jam. Namun memililki kelemahan karena didalam perhitungan harus mencoba seluruh kombinasi. Untuk pengembangan penelitian ini dilakukan penjadwalan dengan mempertimbangkan waktu maintenance.

\section{Daftar Pustaka}

Baker, K. and Trietsch. D. (2009), Principles of Squencing and Scheduling, America, John Wiley \& Sons, Inc. 
Baroto T, (2002), Perencanaan dan Pengendalian Produksi, Ghalia Indonesia, Jakarta

Bedworth, David D., Bailey, James E. (1987), Intregated Production Control Systems. Singapore, John Wiley and Sons Inc.

Febianti, E., Irman, A. S, dan Fitra, J. (2019), Usulan Penjadwalan Produksi Baja Profil Menggunakan Metode Nawaz Enscore And Ham dan Algoritma Simulated Annealing, in Prosiding Seminar Nasional, Sains dan Teknologi, Jakarta

Febianti, E, Irman A. S, dan M. Zikry, (2017), Penjadwalan Produksi Flowshop Dengan Metode Campbell Dudek Smith, Nawaz Enscore Ham dan Heuristic Pour, in Seminar Nasional Teknologi.

Ginting, R. (2009), Penjadwalan Mesin. Yogyakarta : Graha Ilmu.

Irman A. S, Febianti E, and Khasanah U. (2019), Minimizing Makespan on Flow Shop Scheduling Using Campbel Dudek And Smith, Particle Swarm Optimization, and Proposed Heuristic Algoritm, Broad Exposure on Science and Technology (BEST 2019) Conference, Universitas Sultan Ageng Tirtayasa. Indonesia.

Muharni., Y, Kulsum, dan Utami., A, D. (2019), Usulan Penjadwalan Produksi Pipa ERW Menggunakan Metode NEH dan Genethic Algorithm, Jurnal Teknik Mesin Untirta, vol. V, pp. 2938.

Pambudi, A. R. (2016), Usulan Penjadwalan Produksi dengan Menggunakan Metode Campbell Dudek Smith dan Heuristic Pour Melalui Pendekatan Line Balancing (Studi Kasus di IKM Sandal Hotel Permata), Tugas Akhir, Jurusan Teknik Industri Universitas Sultan Ageng Tirtayasa, Cilegon.

Pinedo. M.L. (2012), Scheduling: Theory, Algorithms and System, New Jersey: Springer.

Pour, H. Davoud. (2010), A New Heuristic for n-job m-Machine Flowshop Problem, Journal International Production Planning Control, vol. 12, no. 7.

Widodo, D. S. (2014), Pendekatan Algoritma Cross Entropy Genetic Algorithm Untuk Menurunkan Makespan Pada Penjadwalan Flow Shop, Journal of Engineering and Management in Industrial System, p. vol 2. 